\title{
Case Report: A Case of Acute Intravascular Hemolysis in Dengue Fever
}

\author{
Kolitha H. Sellahewa, ${ }^{1}$ Mohan P. Kumaratne,${ }^{2 \star}$ Shane Halpe, ${ }^{1}$ and Kavindya Marapana ${ }^{1}$ \\ ${ }^{1}$ Dr. Neville Fernando Teaching Hospital, Malabe, Sri Lanka; ${ }^{2}$ Fountain Valley Regional Hospital, Fountain Valley, California
}

\begin{abstract}
Acute intravascular hemolysis (AIH) with hemoglobinuria is a rare complication of dengue viral infection. Review of the literature revealed only one report of $\mathrm{AlH}$ as a complication of dengue fever (DF). We report a case of $\mathrm{AlH}$ with massive hemoglobinuria in a 17-year-old Sri Lankan male, in the febrile phase of DF. This unusual and rare complication warranted forced diuresis, to prevent acute kidney injury. This was a departure from the recommended fluid therapy for DF.
\end{abstract}

\section{INTRODUCTION}

Dengue is the most common arboviral infection and is endemic in Southeast Asia. ${ }^{1,2}$ Dengue viral infection (DVI) has diverse clinical presentations ranging from the more common and usually benign dengue fever (DF) to the less prevalent, but more serious severe dengue (SD), which encompasses dengue hemorrhagic fever (DHF) and dengue shock syndrome (DSS). ${ }^{1-3}$

Complications of DVI are not uncommon. Cardiac, ${ }^{4}$ neurological, ${ }^{5,6}$ ophthalmological, ${ }^{7,8}$ hepatic, ${ }^{9}$ pulmonary, ${ }^{10}$ and renal complications ${ }^{11,12}$ have been regularly reported in medical literature. Hematological disturbances are common to both DF and DHF. ${ }^{13,14}$ However, thrombocytopenia and clinical bleeding such as petechiae, ecchymosis, and gum bleeding are often mild. In DHF, severe mucosal bleeding manifesting as hematemesis, melena, menorrhagia, and concealed internal bleeding may occur and is a reflection of a severe disease. Two cases of hemolytic anemia complicating DHF have been reported. ${ }^{15,16}$ We found only one report of three cases of acute intravascular hemolysis $(\mathrm{AlH})$ in a study of DVI from China. ${ }^{17}$ Here, we report on a 17-year-old Sri Lankan male with DF, complicated by $\mathrm{AlH}$ with massive hemoglobinuria in the febrile phase of the illness. This case is unique because this complication necessitated forced diuresis with boluses of isotonic saline and furosemide to prevent acute kidney injury (AKI), in addition to the maintenance fluid therapy used in the management of DF.

\section{CASE REPORT}

A 17-year-old adolescent male, was in good health, until 3 days before admission when he developed fever. Fever was accompanied by chills, backache, generalized malaise, anorexia, and an episode of vomiting. On the first day of fever, he was seen by a primary care physician and was treated with loratadine, paracetamol, and ciprofloxacin. He denied any headache, retro orbital pain, myalgia, abdominal pain, or skin rashes. He did not complain of any change in color of urine, dysuria, frequency, flank, or supra pubic pain. He had no past history of DF.

On day 3 of fever, he presented to the hospital and was admitted to the medical unit. On admission, the patient was a fairly nourished young man, who was febrile and ill looking, but did not appear to be dehydrated or in any acute

*Address correspondence to Mohan P. Kumaratne, Fountain Valley Regional Hospital, Fountain Valley, CA. E-mail: mohankum@msn.com distress. Vital signs were as follows: temperature, $101^{\circ} \mathrm{F}$; pulse, 96/minutes; respiratory rate, 22/minutes; BP, 110/70; and weight, $51 \mathrm{~kg}$.

There was no pallor, icterus, skin rashes, lymphadenopathy, or peripheral edema. His cardiac, respiratory, abdominal, and neurological examinations were normal. On admission, dengue non-structural protein 1 (NS1) antigen was positive by the biosynex dengue test. The rest of the laboratory findings are shown in Tables 1 and 2. On the evening of admission, his urine was found to be black in color (Figure 1). The black urine was due to hemoglobinuria resulting from $\mathrm{AlH}$. All urine samples since then were examined at the bedside and were consistently black in color.

On further inquiry, the patient denied any episodes of black or red urine in the past. There was no past history or family history suggestive of hemolytic anemia. There was no history of recent travel or bathing in rivers. Review of systems was unremarkable, and specifically there was no history of recurrent abdominal pain, jaundice, or anemia. He had not taken any medications, except the ones prescribed by the primary care doctor as noted previously. The patient had not ingested any dyes, toxins, or foods that may have caused the urine to turn dark red or black. The patient has not had any surgeries and the patient denied any allergies to medications or recent blood transfusions. The patient is a student who lives in a suburb of Colombo and admitted to being bitten by mosquitoes.

The patient continued to have fever with the passage of black-colored urine. Despite the unusual color of the urine, he was clinically stable and the renal functions remained within normal limits. Ultrasound scan of the abdomen and chest did not reveal any abnormalities or fluid leakage into the peritoneal or pleural cavities. He was managed with paracetamol, monitoring of vital signs, and close observation for evidence of plasma leakage. Maintenance quantum of fluid was administered both intravenously and orally in accordance with the Sri Lankan national guidelines for the febrile phase of DF. ${ }^{18}$

To prevent AKI secondary to hemoglobinuria, the patient was administered repeated boluses of isotonic saline $(10 \mathrm{~mL} / \mathrm{kg})$ with $40 \mathrm{mg}$ of IV furosemide from the inception of hemoglobinuria on day 1 of hospitalization (i.e., day 3 of illness) until day 6 (i.e., day 9 of illness). On administering the fluid boluses, the patient's urine became less dark (Figure 2); however, the color reverted to black when the fluid intake was reduced to the maintenance fluid regimen. All the samples of urine voided after forced diuresis were inspected at the bedside, and fluid boluses were repeated on an ad hoc basis 
TABLE 1

Relevant hematology and biochemistry investigations, by the day of illness

\begin{tabular}{|c|c|c|c|c|c|}
\hline Laboratory investigations & Day 3 & Day 5 & Day 8 & Day 10 & Normal range \\
\hline Hemoglobin & 14 & 12.9 & 10.4 & 7.6 & $12-17 \mathrm{~g} / \mathrm{dL}$ \\
\hline $\mathrm{MCV}$ & 89.2 & 89.4 & 97.3 & 98.9 & $76-96 \mathrm{fL}$ \\
\hline $\mathrm{MCHC}$ & 35.3 & 34.5 & 32.4 & 31.9 & $31-35 \mathrm{~g} / \mathrm{dL}$ \\
\hline Red blood cell count & 4.45 & 4.13 & 3.30 & 2.46 & $3.8-5.5 \times 10^{6} / \mathrm{uL}$ \\
\hline Hematocrit & 39.7 & 36.8 & 32.1 & 23.7 & $36-50 \%$ \\
\hline White blood cell count & 5.23 & 4.79 & 6.72 & 7.7 & $4.0-10 \times 10^{3} / \mathrm{uL}$ \\
\hline Platelet count & 113 & 63 & 74 & 150 & $150-410 \times 10^{3} / \mathrm{uL}$ \\
\hline Reticulocyte count & - & $0.5 \%$ & - & - & $0.5-1.5 \%$ \\
\hline Indirect Coomb's test & - & negative & - & - & - \\
\hline Direct Coomb's test & - & negative & - & - & - \\
\hline Total bilirubin & - & 1.33 & 3.14 & - & $0.3-1.2 \mathrm{mg} / \mathrm{dL}$ \\
\hline \multicolumn{6}{|l|}{ Serum enzymes } \\
\hline Alanine aminotransferase & 78.8 & 209.9 & - & - & $<50 \mathrm{U} / \mathrm{L}$ \\
\hline Aspartate aminotransferase & 198.6 & 542.5 & - & - & $<50 U / L$ \\
\hline Creatine kinase & - & 1,007 & - & - & $<171 \mathrm{U} / \mathrm{L}$ \\
\hline Lactate dehydrogenase & - & 2,617 & 3,199 & - & 208-378 U/L \\
\hline $\mathrm{Na}$ & 136 & 135 & 143 & - & $136-146 \mathrm{mmol} / \mathrm{L}$ \\
\hline $\mathrm{K}$ & 3.27 & 3.89 & 3.74 & - & $3.5-5.1 \mathrm{mmol} / \mathrm{L}$ \\
\hline Urea & - & 25.6 & - & - & $17-43 \mathrm{mg} / \mathrm{dL}$ \\
\hline Serum creatinine & 1.05 & 0.93 & 0.89 & - & $0.84-1.25 \mathrm{mg} / \mathrm{dL}$ \\
\hline
\end{tabular}

whenever the urine was black in color. The fluid therapy was aggressive and dynamic to match the dynamics of ongoing AlH and hemoglobinuria. This required a total of three boluses of $0.9 \%$ saline per day. The total fluid intake of both oral and intravenous with the maintenance quantity was $4 \mathrm{~L}$ per day.

On day 8 of illness, he became afebrile and entered the convalescent phase of DF. The urine persisted to be dark in color until day 9 of the illness. On day 10 of illness, the urine color started to normalize and became light pink (Figure 3 ). He remained clinically stable throughout his hospital stay and recovered uneventfully and was discharged home on the 11th day of illness.

\section{DISCUSSION}

The patient was a 17-year-old adolescent male who presented to hospital with an acute febrile illness of 3 days duration in a region of the world with a high prevalence of DVI. The diagnosis of DVI was established on admission by a positive dengue NS1 antigen test. The patient's vital signs were stable, and he had no clinical evidence of SD such as DHF or DSS. However, on the evening of admission, the patient developed black/cola-colored urine. The differential diagnosis of black/cola-colored urine is hematuria, hemoglobinuria, myoglobinuria, bilirubinuria, and pseudohematuria due to ingestion of toxins, certain medications, and foods.

In our patient, the black urine was due to hemoglobinuria because his urine spectrophotometry was positive for hemoglobin and he had only $2-5$ red blood cells per high power field (HPF) on urine microscopy. His hemoglobinuria was secondary to AlH which was established by the presence of anemia, bilirubinemia, and elevated lactate dehydrogenase. ${ }^{19}$ Free hemoglobin in the serum, which is not cleared by tubular reabsorption in the kidney, manifests as hemoglobinuria, which imparts a black color to urine. Common causes for $\mathrm{AlH}$ with hemoglobinuria such as autoimmune hemolytic anemia, falciparum malaria, microangiopathic hemolytic anemia, venomous snake bites endemic in Sri Lanka, incompatible blood transfusions, G6PD deficiency, and ingestion of aniline dyes and other poisons were excluded by a combination of history, examination and laboratory investigations. Ciprofloxacin which the patient took on the first day of fever can rarely cause immune-mediated intravascular hemolysis. ${ }^{20}$ This possibility is very unlikely in our patient as the Coomb's test was negative. In our clinical practice, $\mathrm{AlH}$

TABLE 2

Other investigations, by day of illness

\begin{tabular}{|c|c|c|}
\hline Investigation & Day 3 & Day 5 \\
\hline Dengue NS1 antigen & Positive & - \\
\hline Ultrasound Chest and abdomen & - & $\begin{array}{l}\text { No evidence of plasma leakage to pleural } \\
\text { or peritoneal cavities }\end{array}$ \\
\hline Urine for bilirubin & - & Negative \\
\hline Urine for myoglobin & - & Negative \\
\hline Urine for free hemoglobin & - & Positive \\
\hline Plasmodium falciparum antigen & - & Negative \\
\hline Blood picture & 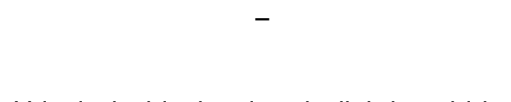 & $\begin{array}{l}\text { Occasional spherocytes, bite cells, and } \\
\text { blister cells. Lymphocytic } \\
\text { predominance with viral forms. }\end{array}$ \\
\hline Urinalysis & $\begin{array}{l}\text { Urinalysis: black colored; slightly turbid; } \\
\text { protein, 1+; blood, 1+; pus cells, } \\
\text { 2-3/HPF; red cells, 2-3/HPF; no casts } \\
\text { seen. }\end{array}$ & - \\
\hline
\end{tabular}




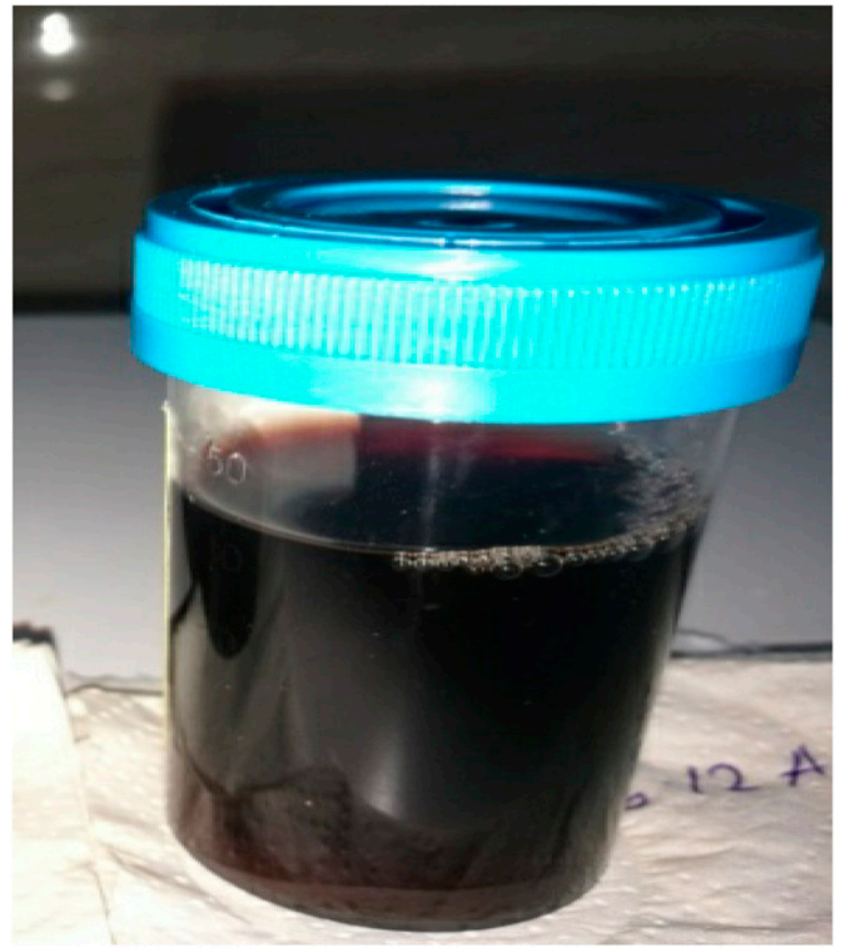

FIGURE 1. Black urine on day 1 of admission (day 3 of illness). This figure appears in color at www.ajtmh.org.

with associated hemoglobinuria is usually encountered in patients with G6PD deficiency. But in our patient, no incriminating factors such as the ingestion of Acalypha indika, fava beans, sulphonamides, antimalarials, or consanguinity in the family could be elicited in the history. ${ }^{21-26}$ Thus, by a

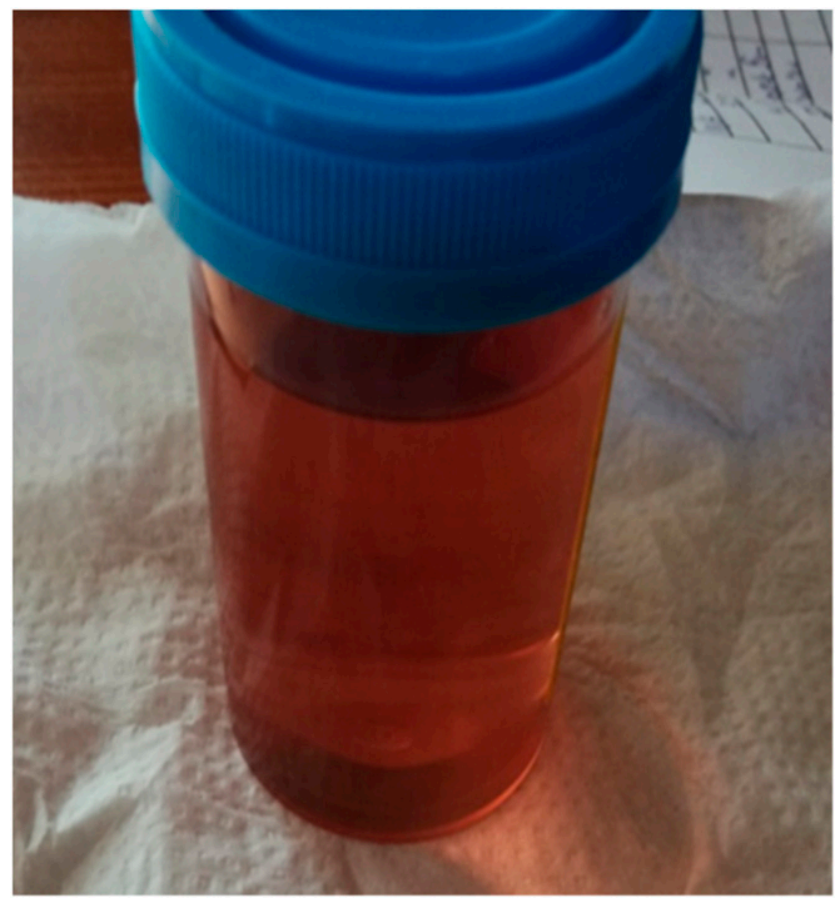

FIGURE 2. Amber-colored urine following forced diuresis on day 2 of hospitalization (day 4 of illness). This figure appears in color at www.ajtmh.org.

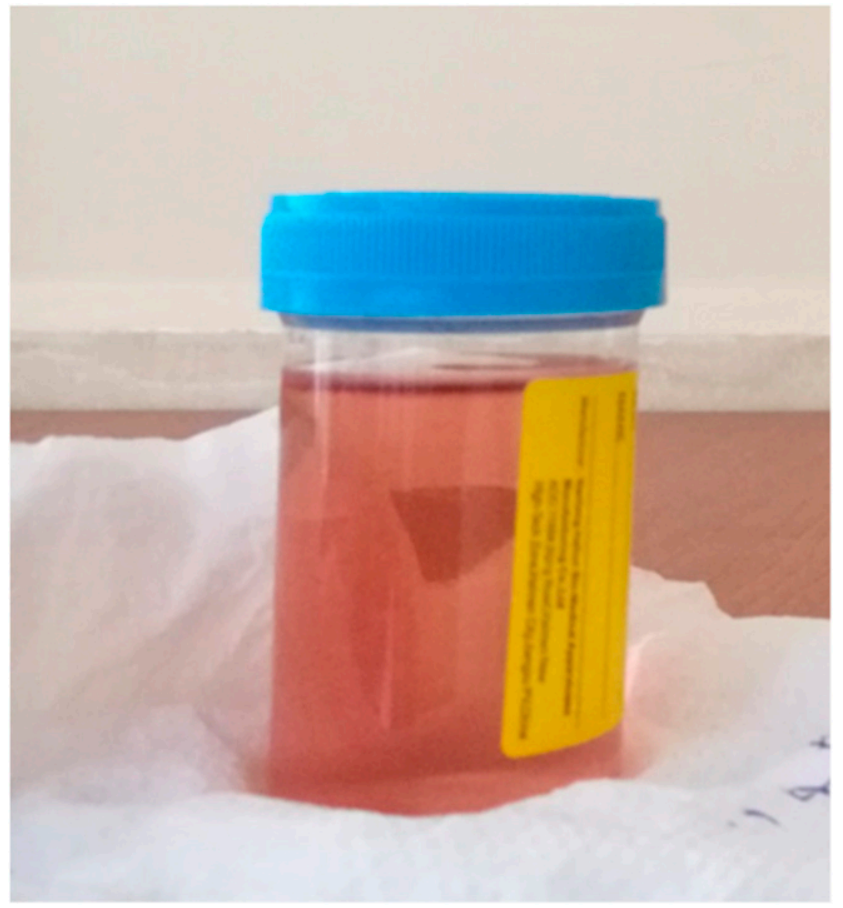

FIGURE 3. Light pink urine color on the day of discharge (day 11 of illness). This figure appears in color at www.ajtmh.org.

process of exclusion we attributed the $\mathrm{AlH}$ and massive hemoglobinuria to DF.

During $\mathrm{AlH}$, red cell lysis releases hemoglobin $(\mathrm{Hb})$ into the circulation where it binds to the carrier protein haptoglobin. Once the haptoglobin binding capacity of plasma is exceeded, free $\mathrm{Hb}$ can be detected in the plasma. Free $\mathrm{Hb}$ is filtered through the glomerular membrane in the kidney and in the proximal convoluted tubule (PCT) $\mathrm{Hb}$ is reabsorbed. Once the reabsorptive capacity of the PCT is exceeded, $\mathrm{Hb}$ is excreted in the urine and imparts the characteristic black color.

Hemoglobinuria related $\mathrm{AKI}$ is driven by intrarenal oxidative reactions triggering a heme toxicity response due to the tubular deposit of hemosiderin. ${ }^{27,28} \mathrm{AKI}$ can be prevented by ensuring a rapid tubular urine flow by forced diuresis. We achieved this objective by liberal use of intravenous $0.9 \%$ saline and IV furosemide. For a favorable outcome, it is essential to initiate diuresis very early at the inception of hemoglobinuria and must be sustained until hemolysis ceases and urine is no longer black.

Fluid management in a patient with dengue infection is critical to ensure a favorable outcome. Guideline recommendation of fluid for the febrile phase of both DF and DHF is only the maintenance quantity which should not exceed a maximum of $2,500 \mathrm{~mL} /$ day of both oral and intravenous fluid. Judicious fluid therapy was adjusted hourly based on physiological parameters of pulse pressure, heart rate, urine output, and hematocrit enables accurate fluid adjustments to prevent both fluid overload and shock. In this patient, we had to exceed the guidelinerecommended fluid quota to achieve the primary goal of preventing $\mathrm{AKI}$ by ensuring a rapid tubular urine flow in the setting of ongoing AlH and hemoglobinuria. Despite the liberal use of IV saline and furosemide, there was no fluid overloading as evidenced by the absence of tachycardia, tachypnea, dyspnea, peripheral edema, elevated JVP, clear lung bases, and an $\mathrm{spO}_{2}>95 \%$ while breathing atmospheric air. 
Clinicians should consider DVI as a possible cause for AlH and hemoglobinuria. Accurate identification of the clinical type as DF or DHF, and the phase of the illness as febrile, critical, or convalescent during which the AlH sets in will be of crucial importance in fluid management. For a patient with DHF in the critical phase, aggressive fluid therapy exceeding the calculated fluid quota in an attempt to prevent $\mathrm{AKI}$ by inducing diuresis in the setting of ongoing hemoglobinuria could aggravate the tendency for fluid overloading and leak of fluid into third spaces with attended respiratory compromise. Intravenous furosemide at this stage could lead to shock. Similarly, too much of fluid in the 24 hours of equilibration at the end of the critical phase and advent of convalescence could also lead to fluid overloading due to reabsorption of leaked fluid into the vascular compartment. The use of blood transfusions, IV saline, and IV furosemide during the critical and equilibration phases of DHF complicated with AlH would, thus, be a fine balancing act in preventing $\mathrm{AKI}$ on one hand by inducing forced diuresis, and preventing both fluid overload and shock on the other hand by the same intervention. This was not a concern for our patient as he had DF and not DHF and, hence, no critical phase and plasma leakage. In either case, a favorable outcome is yet feasible by a sound understanding of the clinical types of DVI as DF or DHF, correct identification of the phase of illness, close monitoring, and proper interpretation of physiological parameters reflecting cardiovascular compensation to fluid leakage, and the dynamics of $\mathrm{AlH}$ and hemoglobinuria with a propensity to develop AKI.

\section{CONCLUSION}

Acute intravascular hemolysis with hemoglobinuria is a rare complication of DF. To prevent AKI, forced diuresis is indicated. This is a departure from the national guidelines on fluid therapy in DF, which recommends a maximum of $2,500 \mathrm{~mL} / 24$ hours of both oral and intravenous fluids. Despite these recommendations, forced diuresis is a useful intervention to prevent AKI when DF is complicated with $\mathrm{AlH}$ and hemoglobinuria. However, in this clinical setting, it must be carried out with close clinical and laboratory monitoring to prevent cardiac and respiratory complications due to fluid overload.

Received October 7, 2019. Accepted for publication December 2, 2019.

Published online January 6, 2020.

Acknowledgments: We are grateful to S. Sivakumaran and A. A. A. Riyaaz for giving us access to the patient and useful comments on management and Jasmine Cisneros, $\mathrm{RN}$, for proof reading and formatting the document. The American Society of Tropical Medicine and Hygiene (ASTMH) assisted with publication expenses.

Authors' addresses: Kolitha H. Sellahewa, Shane Halpe, and Kavindya Marapana, Dr. Neville Fernando Teaching Hospital, Malabe, Sri Lanka, E-mails: kolithah@gmail.com, shanehalpe@gmail.com, and kavi777@ live.com. Mohan P. Kumaratne, Fountain Valley Regional Hospital, Fountain Valley, CA, E-mail: mohankum@msn.com.

\section{REFERENCES}

1. Simmons CP, Farrar JJ, Van Vinh Chau N, Wills B, 2012. Current concepts: dengue. N Engl J Med 366: 1423-1432.

2. Kularatne SA, 2015. Dengue fever. BMJ 351: h4663.

3. Muller DA, Depelsenaire AC, Young PR, 2017. Clinical and laboratory diagnosis of dengue virus infection. $J$ Infect Dis 215 (Suppl 2): S89-S95.
4. Biswas S, Kumar P, Tansir G, Biswas A, 2019. Case report: cardiac tamponade in dengue hemorrhagic fever: an unusual manifestation of a common disease. Am J Trop Med Hyg 101: 448-450.

5. Verma R, Sahu R, Holla V, 2014. Neurological manifestations of dengue infection: a review. J Neurol Sci 346: 26-34.

6. Weerasinghe WS, Medagama A, 2019. Dengue hemorrhagic fever presenting as encephalitis: a case report. J Med Case Rep 13: 278.

7. Merle H, Donnio A, Jean-Charles A, Guyomarch J, Hage R, Najioullah F, Césaire R, Cabié A, 2018. Ocular manifestations of emerging arboviruses: dengue fever, Chikungunya, Zika virus, West Nile virus, and yellow fever. J Fr Ophtalmol 41: 659-668.

8. Ng AW, Teoh SC, 2015. Dengue eye disease. Surv Ophthalmol 60: 106-114.

9. Dalugama C, Gawarammana IB, 2017. Dengue hemorrhagic fever complicated with acute liver failure: a case report. J Med Case Rep 11: 341.

10. de Almeida RR, Paim B, de Oliveira SA, Souza AS Jr., Gomes ACP, Escuissato DL, Zanetti G, Marchiori E, 2017. Dengue hemorrhagic fever: a state-of-the-art review focused in pulmonary involvement. Lung 195: 389-395.

11. Vachvanichsanong $P$, Thisyakorn $U$, Thisyakorn $C, 2016$. Dengue hemorrhagic fever and the kidney. Arch Virol 161: 771-778.

12. Dalugama C, Gawarammana IB, 2018. Lessons learnt from managing a case of dengue hemorrhagic fever complicated with acute liver failure and acute kidney injury: a case report. J Med Case Rep 12: 215.

13. Gubler DJ, 1998. Dengue and dengue hemorrhagic fever. Clin Microbiol Rev 11: 480-486.

14. Pang X, Zhang R, Cheng G, 2017. Progress towards understanding the pathogenesis of dengue hemorrhagic fever. Virol Sin 32: 16-22.

15. Aye M, Cabot J, William LWK, 2016. Severe dengue fever with haemolytic anaemia. A case Study. Trop Med Infect Dis 1: E6.

16. Medagoda K, Gunathilaka SB, De Silva HJ, 2003. A case of selflimiting Coomb's negative haemolytic anaemia following dengue shock syndrome. Ceylon Med J 48: 147-148.

17. Qiu FX, Chen QQ, Ho QY, Chen WZ, Zhao ZG, Zhao BW, 1991. The first epidemic of dengue hemorrhagic fever in the People's Republic of China. Am J Trop Med Hyg 44: 364-370.

18. Ministry of Health-Sri Lanka, 2012. National Guidelines on Management of Dengue Fever and Dengue Hemorrhagic Fever. Available at: http://www.epid.gov.lk/. Accessed December 27, 2019.

19. Brodsky RA, 2019. Warm autoimmune hemolytic anemia. N Engl J Med 381: 647-654.

20. Garbe E et al., 2011. Drug induced immune haemolytic anaemia in the Berlin case-control surveillance study. Br J Haematol 154: 644-653.

21. Barber BE, Grigg MJ, Piera KA, William T, Cooper DJ, Plewes K, Dondorp AM, Yeo TW, Anstey NM, 2018. Intravascular haemolysis in severe Plasmodium knowlesi malaria: association with endothelial activation, microvascular dysfunction, and acute kidney injury. Emerg Microbes Infect 7: 106.

22. Cappellini MD, Fiorelli G, 2008. Glucose-6-phosphate dehydrogenase deficiency. Lancet 371: 64-74.

23. Youngster I, Arcavi L, Schechmaster R, Akayzen Y, Popliski H, Shimonov J, Beig S, Berkovitch M, 2010. Medications and glucose-6-phosphate dehydrogenase deficiency. Drug Safety 33: 713-726.

24. Luzzatto L, Seneca E, 2014. G6PD deficiency: a classic example of pharmacogenetics with on-going clinical implications. $\mathrm{Br} \mathrm{J}$ Haematol 164: 469-480.

25. Beutler E, 2008. Glucose-6-phosphate dehydrogenase deficiency: a historical perspective. Blood 111: 16-24.

26. Sellahewa K, 1994. Acalypha indica induced haemolysis in G6PD deficiency. Ceylon Med J 39: 145.

27. Deuel JW, Schaer CA, Boretti FS, Opitz L, Garcia-Rubio I, Baek JH, Spahn DR, Buehler PW, Schaer DJ, 2016. Hemoglobinuriarelated acute kidney injury is driven by intrarenal oxidative reactions triggering a heme toxicity response. Cell Death Dis 7: e2064.

28. Rifkind JM, Mohanty JG, Nagababu E, 2015. The pathophysiology of extracellular hemoglobin associated with enhanced oxidative reactions. Front Physiol 5: 500. 